\title{
How Songkick is using Technology to Change Live Music
}

\author{
Dan Crow \\ Songkick \\ London, UK \\ dancrow@songkick.com
}

\section{KEYNOTE ABSTRACT}

Songkick has been at the forefront of live music technology for nearly a decade now. We believe that a concert can be an extraordinary experience and we want more people to enjoy great live music. So we spend every waking hour thinking about how to make going to live music better.

I will talk about how some of the experiments we have run, some of the products we have released and how we use technology to improve the experience for fans and artists. Our services are used by more than 10 million music fans from around the world every month. This scale gives us huge insight into where the fans are and who they want to see play live.

I will talk about Tourbox, our tool for artists to make their lives better and their tours more popular. I will talk about Detour, our crowdsourcing experiment for routing tours. I will talk about our analytics and data science systems that let us see how the live music industry works and where it could be made better. 